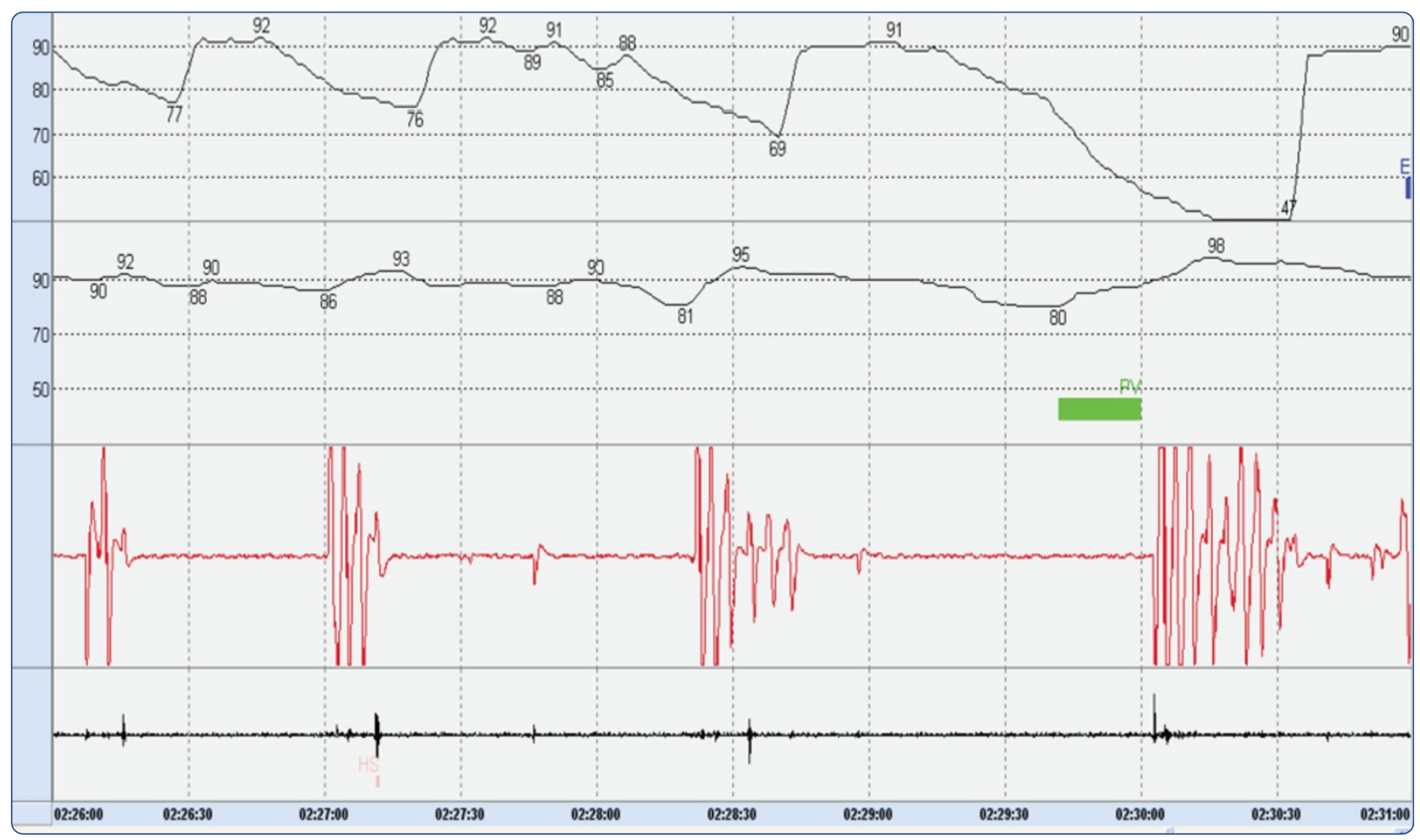

\title{
Incidence of perioperative sleep-disordered breathing in patients undergoing major surgery: a prospective cohort study
}

Roggenbach et al. 


\title{
Incidence of perioperative sleep-disordered breathing in patients undergoing major surgery: a prospective cohort study
}

\author{
Jens Roggenbach ${ }^{1 *}$, Patrick Saur ${ }^{1}$, Stefan Hofer ${ }^{1}$, Thomas Bruckner ${ }^{2}$, Michael Preusch ${ }^{3}$, Remo Carbone ${ }^{4}$ \\ and Andreas Walther ${ }^{4}$
}

\begin{abstract}
Background: Major surgery might have a modulating effect on nocturnal breathing patterns. The incidence and course of perioperative sleep-disordered breathing in individuals without a previous diagnosis of obstructive sleep apnea has not been investigated sufficiently so far.

Methods: In this study, polygraphic recordings have been obtained from 37 inpatients without a diagnosis of obstructive sleep apnea syndrome during the preoperative night before and six nights following major surgical procedures.

Eligible patients consenting to participate in this study underwent polygraphic recordings including four items $\left(\mathrm{O}_{2}\right.$-saturation, pulse, nasal air flow and snoring) during the study period. Polygraphic data obtained from the postoperative recordings were compared to preoperative recordings.

Results: Median (IQR [range]) apnea-hypopnea-index (AHI) for the whole group was 6,0 (2,5 - 14,7 [0-32,6]) in the preoperative night and increased in the following six nights post surgery: second night: 5,6 (2,6-15,0 [1,1 - 59,3]); third night: $16,9(5,6$ - 38,8 [2,9 - 64,3]); fourth night: 11,6 (5,9 - 17,3 [0,4 - 39,3]); fifth night: 15,2 (5,7 - 22,2 [0,2 - 55,5]); sixth night: $22,5(5,2-35,4[0,2-67,7])$. AHI-scores of the third to sixth night post surgery differed significantly from data observed in the preoperative night.

Conclusion: A significant increase in the AHI occurred frequently after major surgical procedures in the late postoperative period. Sleep-disordered breathings in the late postoperative period deserve attention, as they potentially increase the risk of postoperative complications.
\end{abstract}

Keywords: Obstructive sleep apnea, Major surgery, Sleep-disordered breathing, Postoperative hypoxemia

\section{Introduction}

Sleep-disordered breathing (SDB) is a common disorder, with an estimated prevalence of $9 \%$ for women and $24 \%$ for middle-aged male adults. In the elderly, the prevalence is even higher [1-3]. It is characterized by intermittent cessation of normal respiratory patterns during sleep, most frequently due to a periodic loss of pharyngeal muscle tone with consecutive narrowing of the upper airway. In the most common form of SDB, the obstructive sleep apnea syndrome (OSAS), recurrent loss of airway patency

\footnotetext{
* Correspondence: jens.roggenbach@med.uni-heidelberg.de

'Department of Anaesthesiology and Intensive Care Medicine, University

Hospital, University of Heidelberg, Heidelberg, Germany

Full list of author information is available at the end of the article
}

causes intermittent hypoxemia and hypercapnia, which is associated with endogenous stress, sympathoadrenergic activation and recurrent arousals. Severe OSAS can lead to sleep fragmentation and interruption of the normal sleep architecture. In the perioperative setting OSAS has been associated with respiratory complications $[4,5]$, myocardial ischemia [6], arrhythmias, postoperative delirium, bleeding and wound infections [7-10]. It is noteworthy that even though SDB and OSAS have been recognized as risk factors for perioperative complications, they mostly remain undiagnosed.

While the obstructive sleep apnea syndrome (OSAS) has been considered as a significant risk factor for perioperative morbidity, especially due to respiratory complications 
in the early perioperative episode, the dynamic process of postoperative sleep-associated respiratory disorders still remains to be elucidated in individuals without the diagnosis of OSAS. Since most individuals with OSAS are unaware of their disorder [11], it was the aim of this study to examine the course of SDB in the postoperative period in individuals undergoing major surgical procedures without a previous diagnosis of OSAS.

\section{Methods}

This study was designed as a pilot trial, since literature provided only insufficient information on the postoperative course of SDB in individuals without previous diagnosis of OSAS. The institutional ethics committee of the university of Heidelberg approved the study. Between March and July 2010 written consent was obtained from inpatients undergoing major abdominal or urological surgery who were willing and eligible to participate in this study. Inclusion criteria were: age $>18$ yrs, no previous diagnosis of sleep apnea, exclusion of any mental disability and a planned surgical procedure, requiring a postoperative in-hospital stay for at least six days.

Polygraphic recordings of nocturnal breathing disorders were performed with a portable polygraph (MiniScreen 4, Heinen-Löwenstein, Bad Ems, Germany). The Mini-Screen 4 Polygraph measures heart rate and oxygen saturation with a pulse oxymeter and respiration and snoring via a nasal probe. Measurements were obtained from each participant from the night before surgery, and whenever possible, from the following six postoperative nights. Data on relevant coexisting diseases, permanent medication and administered analgesics and sedatives were collected for each patient. A check-up and adjustment of the polygraph was done every evening. Two trained physicians evaluated the polygraphic recordings. Sleep associated respiratory disorders were classified according to the American Academy of Sleep Medicine (AASM) criteria for the scoring of sleep and associated events [12]. According to the respiratory scoring rules published by the AASM an apnea was scored, when respiratory flow dropped by $\geq 90 \%$ of baseline for at least 10 seconds. A hypopnea was scored when nasal pressure signal excursions dropped by $\geq 50 \%$, with a duration of at least 10 seconds, accompanied by a oxygen desaturation of at least 3\% [12]. Exclusion criteria for nocturnal measurements were loss of the nasal probe or the pulse oxymeter during the night, or a recording time less than 6 hrs.

The apnea-hypopnea-index (AHI) expresses the mean number of apneas and hypopneas per hour sleep. In this study, a pre-operative AHI-Index $<5$ was considered unsuspicious for OSAS.

Since this was a pilot trial, no data on normal pre- and postoperative AHI- values were available. In an a priori power analysis was performed with mean preoperative AHI- values $\left(\mu_{1}\right)$, mean postoperative AHI-values $\left(\mu_{2}\right)$ and the standard deviation $(\sigma)$. Based on the assumptions $\mu_{1}=5, \mu_{2}=10$ and $\sigma=5$ a sample size of $n=10$ was calculated with a significance level of $\mathrm{p}=0.05$ and a power of 0.8. Statistical analysis were performed with SPSS, Statistics pack 20.0 software (Chicago, IL, USA). The normality of data distribution was determined using the Kolmogorov-Smirnov test. Patient characteristics are expressed as mean and standard deviation for normally distributed data and as median, interquartile range (IQR) and range for non-normally distributed data. Postoperative measurements were compared with preoperative values using Boferroni adjusted Wilcoxon signed-rank tests. A value of $\mathrm{p}<0,05$ was considered significant.

\section{Results}

Initally 70 patients consented to participate in the study. 19 Patients had to be excluded from the study, either due to insufficient polygraphic recordings preoperatively or during the nights following surgery. 14 patients refused further study participation after surgery. Finally, 37 Patients were included in this study. Patient characteristics are expressed in Table 1 and the type surgery is presented in Table 2. 15 patients (41\%) of all patients consenting to participate, were admitted for prostate surgery. All other patient had major intraabdominal surgery (mainly pancreatic and small bowel surgery, colonic surgery and liver resection). Surgery was performed in all patients under general anesthesia. 13 patients had general anesthesia with neuraxial blockade via epidural catheter. Of which, 12 patients were admitted for visceral surgery. Postoperative pain therapy was performed either with continuous epidural anesthesia with ropivacaine $(0.2 \%)$ or with i.v. opioid boluses and patient controlled analgesia using opioid boluses (piritramide) in all

Table 1 Patient characteristics

\begin{tabular}{ll}
\hline Sex $(\mathrm{m} / \mathrm{f})$ & $29 / 8$ \\
Age (years)- mean \pm SD & $60 \pm 10$ \\
Height $(\mathrm{cm})$ - mean $\pm \mathrm{SD}$ & $177,7 \pm 8,9$ \\
Weight $(\mathrm{Kg})$ - mean $\pm \mathrm{SD}$ & $84,6 \pm 17,1$ \\
BMI- mean \pm SD & $26,6 \pm 3,9$ \\
ASA-class (I/II/II) & $2 / 24 / 11$ \\
NYHA-class $>0(\mathrm{y} / \mathrm{n})$ & $5 / 32$ \\
Diabetes $(\mathrm{y} / \mathrm{n})$ & $6 / 31$ \\
Coronary artery disease $(\mathrm{y} / \mathrm{n})$ & $5 / 32$ \\
Chronic obstructive lung disease $(\mathrm{y} / \mathrm{n})$ & $3 / 34$ \\
Arterial hypertension $(\mathrm{y} / \mathrm{n})$ & $18 / 19$ \\
Renal insufficiency $(\mathrm{y} / \mathrm{n})$ & $7 / 30$ \\
Duration of surgery $(\mathrm{min} \pm \mathrm{SD})$ & $234 \pm 94$ \\
\hline
\end{tabular}


Table 2 Type of surgery performed in study sample

\begin{tabular}{ll}
\hline Pancreatic surgery & $\mathrm{n}=5$ \\
Colorectal surgery & $\mathrm{n}=5$ \\
Radical prostatectomy & $\mathrm{n}=5$ \\
Laparoscopic prostatectomy & $\mathrm{n}=10$ \\
Hemihepatectomy & $\mathrm{n}=3$ \\
Peritonectomy & $\mathrm{n}=2$ \\
Small bowel surgery & $\mathrm{n}=4$ \\
Others & $\mathrm{n}=3$ \\
\hline
\end{tabular}

cases. All patients received either metamizol or nonsteroidal anti-inflammatory drugs for supplementary pain therapy. After leaving the post-anaesthesia care unit, none of the examined individuals received supplemental oxygen during the evaluation period. None of the patients examined, spent more than one night in the post-anaesthesia care unit.

No intraoperative complications were observed. During the postoperative period six patients $(16.2 \%)$ had wound healing deficits and two patients had wound infections (5.4\%). Furthermore, pulmonary embolism was diagnosed in two patients and one patient had refractory arterial hypertension.

$41 \%$ of all examined patients showed normal breathing patterns in the preoperative night. However, almost 22\% of all patients had an AHI of 15 or higher (Figure 1).

While pre-surgery polygraphic recordings were obtained from all patients, only four patients continued their participation immediately the first night following surgery. According to patients self-evaluation the study dropout in the first night following surgery was mainly related to postoperative stress. Median (IQR [range]) apnea-hypopnea-index (AHI) for the whole group was

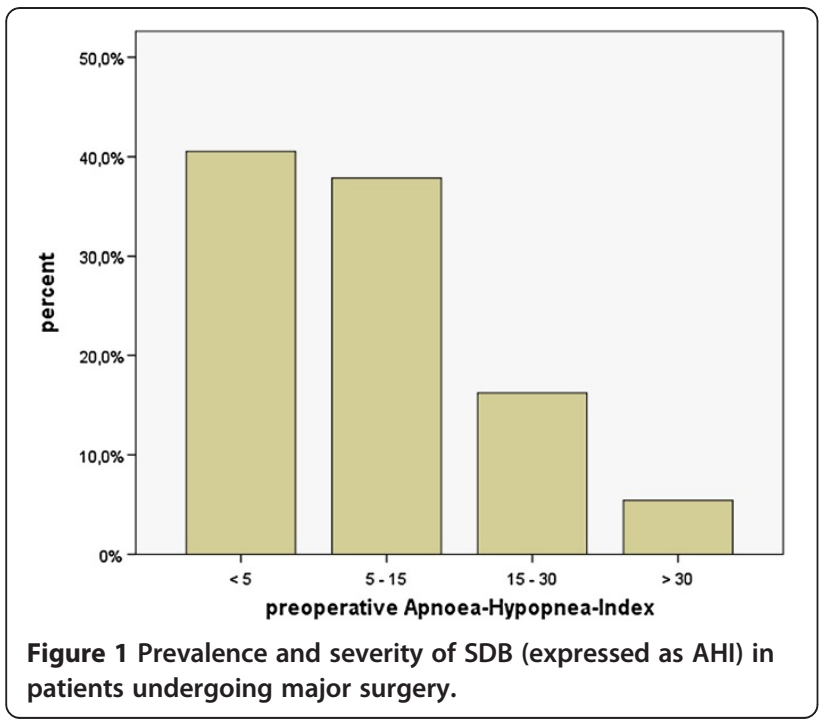

$6,0(2,5-14,7[0-32,6])$ in the preoperative night and increased in the following six nights post surgery: second night: 5,6 (2,6-15,0 [1,1 - 59,3]); third night: 16,9 (5,6 38,8 [2,9 - 64,3]); fourth night: $11,6(5,9-17,3[0,4$ 39,3]); fifth night: 15,2 (5,7 - 22,2 [0,2 - 55,5]); sixth night: 22,5 (5,2 - 35,4 [0,2 - 67,7]) (Table 3). The AHI for the postoperative nights 3 to 6 differed significantly when compared to the preoperative data (preoperative AHI compared to AHI 3. night: $\mathrm{p}=0,01 ; 4$. night $\mathrm{p}=$ 0,$045 ; 5$. night $\mathrm{p}=0,005 ; 6$. night $\mathrm{p}=0,04$ ). The mean duration of apnoeic- and hypopnoeic episodes did not change significantly between the pre-op values and the following nights.

Frequent snoring was reported by 28 patients $(76 \%)$, while only 9 patients (24\%) complained of daytime sleepiness. Neither patients with self-reported snoring nor daytime sleepiness differed in their pre- and postoperative AHI-values from patients without these symptoms. No statistical difference in postoperative AHI values was observed, when comparing postoperative AHI values in patients with and without epidural analgesia in the subgroup of patients that underwent major visceral surgery. No correlation was found between the daily dosing of opioid-based analgesics and the AHI-values during the corresponding night. Sedative agents were given infrequently. Only three patients received benzodiazepines in the night before surgery.

\section{Discussion}

In this pilot study we have observed a high prevalence of SDB and a significant increase in nocturnal AHI-values in surgical patients without a previous diagnosis of OSAS in the first six nights following the surgical procedure. Thus, postoperative SDB appears to be a common phenomenon, which can be found in numerous

Table $3 \mathrm{AHI}$ in the perioperative period: median (IQR [range]) in all examined individuals

\begin{tabular}{|c|c|c|}
\hline & $\begin{array}{l}\text { All individuals } \\
\quad(n=37)\end{array}$ & $\begin{array}{l}\text { Sign. difference to preoperative } \\
\text { values (Wilcoxon-Test - Bonferroni } \\
\text { adjusted) }\end{array}$ \\
\hline $\begin{array}{l}\text { Preoperative } \\
\text { night }(n=37)\end{array}$ & $\begin{array}{c}6,0(2,6-14,7 \\
[0-32,6])\end{array}$ & \\
\hline $\begin{array}{l}\text { 1. Postoperative } \\
\text { night }(n=4)\end{array}$ & $\begin{array}{l}4,6(1,8-9,1 \\
[1,2-10,2])\end{array}$ & \\
\hline $\begin{array}{l}\text { 2. Postoperative } \\
\text { night }(n=18)\end{array}$ & $\begin{array}{c}5,6(2,6-15,0 \\
[1,1-59,3])\end{array}$ & n.s. \\
\hline $\begin{array}{l}\text { 3. Postoperative } \\
\text { night }(n=21)\end{array}$ & $\begin{array}{c}16,9(5,6-38,8 \\
[2,9-64,3])\end{array}$ & $p=0,01$ \\
\hline $\begin{array}{l}\text { 4. Postoperative } \\
\text { night }(n=28)\end{array}$ & $\begin{array}{c}11,6(5,9-17,4 \\
[0,4-39,3])\end{array}$ & $p=0,045$ \\
\hline $\begin{array}{l}\text { 5. Postoperative } \\
\text { night }(n=28)\end{array}$ & $\begin{array}{c}15,2(5,7-22,2 \\
[0,2-55,5])\end{array}$ & $p=0,005$ \\
\hline $\begin{array}{l}\text { 6. Postoperative } \\
\text { night }(n=11)\end{array}$ & $\begin{array}{c}22,5(5,2-35,4 \\
[0,2-67,7])\end{array}$ & $p=0,04$ \\
\hline
\end{tabular}


individuals and which is not restricted to patients with an already known diagnosis of sleep apnea. The severity of perioperative respiratory disturbances were not found to be different in individuals with and without the leading symptoms of OSAS, snoring and daytime sleepiness. Thus, screening for these symptoms to identify patients with undiagnosed OSAS might be of limited value.

The causes for the postoperative deterioration of SDB remain to be elucidated. It has been reported that perioperative analgetic therapy with opioids increases the risk for sleep related respiratory disturbances $[13,14]$. In this study however, we found no difference in the severity of postoperative SDB between patients with epidural analgesia and opioid based patient controlled analgesia. It has been shown that rostral fluid shift during recumbent position reduces upper-airway size and increases the upper airway collapsibility $[15,16]$.

Due to perioperative fluid load, major abdominal surgery is regularly associated with significant fluid accumulation, which has to be eliminated after surgery. It appears reasonable, that perioperative volume retention might contribute to peripharyngeal soft tissue edema and thus, reduced airway patency. Furthermore, abundant literature suggests, that cytokines play an important role in sleep regulation. Especially the cytokines Interleukin1 and Tumor-Necrosis-Factor, which are released after surgery, have been associated with sleep fragmentation, increased non-REM-sleep and suppression of REMsleep [17-19]. Consistent with these observations, previous studies showed a suppression of REM and slow-wave sleep in the early postoperative period with a consecutive REM-rebound later on [20-22]. Increased and prolonged REM-Stages in the late postoperative period have been associated with a loss in pharyngeal musculature tone, predisposing to upper airway obstruction and thus, contributing to nocturnal desaturations $[23,24]$.

As previously mentioned, the majority of OSAS remains undiagnosed in the general population $[1,25]$. Thus, it seems to be a frequent situation that the caretaking physician is confronted with patients suffering from undiagnosed OSAS. Notably, optimal treatment and surveillance of inpatients with OSAS undergoing surgery remains unclear. It has been suggested by the ASA task force on perioperative management of patients with obstructive sleep apnea that individuals with known or suspected OSAS should be monitored with pulse oximetry, until their oxygen saturations remain above $90 \%$ during sleep without supplemental oxygen [26]. However, it appears plausible, that sleep fragmentation and suppression of REM- and slow-wave-sleep might obscure the real incidence of sleep associated respiratory disorders in the early postoperative period. Therefore, after a fallacious uneventful first postoperative night, it might be a misconception to conclude that further monitoring might not be necessary. In this study nocturnal respiratory disturbances occurred primarily in the later postoperative period, when patients have been usually transferred to the regular ward and sufficient surveillance for hypoxemia is usually omitted. Thus, it is conceivable that postoperative sleep associated hypoxemic episodes usually remain unrecognized by professionals. Untreated hypoxemic events might increase postoperative stress and might consequently contribute to perioperative complications. It is worth mentioning that in a previous study on 206 patients with a diagnosis of OSAS that underwent ambulatory surgery, a high incidence of postoperative hypoxemia was found during the first night following ambulatory surgery. This however, was not associated with postoperative complications or unplanned hospital admission [27]. Thus, the meaning of sleep associated postoperative hypoxemia for postoperative complications deserves further investigation.

There are some limitations in the present study. Results of clinical observational studies can be biased by the individuals that are included in the study. It can not be excluded, that especially patients who were susceptible for symptoms of sleep apnea were willing to participate in this study. However, the observed prevalence of SDB in this study sample is comparable with observations from epidemiological studies [11,28].

In this trial, SDB was evaluated with polygraphs, not polysomnography, which might have overestimated the total sleeping time. It is noteworthy that various studies showed a high diagnostic accuracy of polygraphs for detecting SDB $[29,30]$ and thus, it appears unlikely that polysomnography would have revealed significant different results.

In conclusion, the study results show that postoperative SDB is a frequently occurring phenomenon. It particularly happens when at least expected, in the late postoperative period. At this time patients have been usually transferred to the regular ward. It is conceivable that these SDB's are a risk factor for postoperative complications, e.g. cardiac arrhythmias, hypertension, delirium, mood disorders and respiratory complications. Careful screening for suspect signs of SDB might contribute to the identification of patients at risk for postoperative complications.

\section{Competing interests}

The authors specifically do not have any financial conflict of interest related to the sponsor of this study, Heinen + Löwenstein, Bad Ems, Germany. The authors declare that they have no competing interests.

\section{Authors' contributions}

JR: study design, data acquisition and analysis, drafted the article. PS: Critical revision for intellectual content, final approval of the article. SH: Study design, critical revision of the article, final approval of the article. TB: Analysis and data interpretation, final approval of the article. MP: Critical revision for intellectual content, final approval of the article. RC: Acquisition of data, 
analyzed and interpreted data, final approval of the article. AW: Contributed to concept and design, final approval of the article.

\section{Acknowledgement}

We would like thank Doris Kraus from Heinen \& Löwenstein for her valuable contribution to this study.

This work was supported by Heinen + Löwenstein GmbH \& Co. KG, Arzbacher Straße 80, 56130 Bad Ems, Germany.

\section{Author details}

${ }^{1}$ Department of Anaesthesiology and Intensive Care Medicine, University Hospital, University of Heidelberg, Heidelberg, Germany. ${ }^{2}$ Department of Medical Biometry and Informatics, University of Heidelberg, Heidelberg, Germany. ${ }^{3}$ Department of Cardiology, Angiology, Pneumology, University Hospital, University of Heidelberg, Heidelberg, Germany. ${ }^{4}$ Department of Anaesthesiology and Intensive Care Medicine, Katharinen-Hospital, Klinikum Stuttgart, Germany.

Received: 30 November 2013 Accepted: 7 March 2014 Published: 13 March 2014

\section{References}

1. Young T, Palta M, Dempsey J, Skatrud J, Weber S, Badr S: The occurrence of sleep-disordered breathing among middle-aged adults. N Engl J Med 1993, 328:1230-1235.

2. Ancoli-Israel S, Kripke DF, Klauber MR, Mason WJ, Fell R, Kaplan O: Sleep-disordered breathing in community-dwelling elderly. Sleep 1991, 14:486-495.

3. Duran J, Esnaola S, Rubio R, Iztueta A: Obstructive sleep apnea-hypopnea and related clinical features in a population-based sample of subjects aged 30 to 70 yr. Am J Respir Crit Care Med 2001, 163:685-689.

4. Gupta RM, Parvizi J, Hanssen AD, Gay PC: Postoperative complications in patients with obstructive sleep apnea syndrome undergoing hip or knee replacement: a case-control study. Mayo Clin Proc 2001, 76:897-905.

5. Memtsoudis S, Liu SS, Ma Y, Chiu YL, Walz JM, Gaber-Baylis LK, Mazumdar M: Perioperative pulmonary outcomes in patients with sleep apnea after noncardiac surgery. Anesth Analg 2011, 112:113-121.

6. Reeder MK, Muir AD, Foex P, Goldman MD, Loh L, Smart D: Postoperative myocardial ischaemia: temporal association with nocturnal hypoxaemia. Br J Anaesth 1991, 67:626-631.

7. Hwang D, Shakir N, Limann B, Sison C, Kalra S, Shulman L, Souza Ade C, Greenberg $\mathrm{H}$ : Association of sleep-disordered breathing with postoperative complications. Chest 2008, 133:1128-1134.

8. Rosenberg J, Dirkes WE, Kehlet $\mathrm{H}$ : Episodic arterial oxygen desaturation and heart rate variations following major abdominal surgery. $\mathrm{Br} J$ Anaesth 1989, 63:651-654.

9. Kaw R, Golish J, Ghamande S, Burgess R, Foldvary N, Walker E: Incremental risk of obstructive sleep apnea on cardiac surgical outcomes. J Cardiovasc Surg (Torino) 2006, 47:683-689.

10. Rosenberg J, Kehlet H: Postoperative mental confusion-association with postoperative hypoxemia. Surgery 1993, 114:76-81.

11. Young T, Peppard PE, Gottlieb DJ: Epidemiology of obstructive sleep apnea: a population health perspective. Am J Respir Crit Care Med 2002, 165:1217-1239.

12. Iber CA-IS, Chesson A, Quan SF for the American Academy of Sleep Medicine: The AASM Manual for the Scoring of Sleep and Associated Events: Rules, Terminology and Technical Specifications, 1st ed. Westchester, Illinois: American Academy of Sleep Medicine; 2007.

13. Blake DW, Chia PH, Donnan G, Williams DL: Preoperative assessment for obstructive sleep apnoea and the prediction of postoperative respiratory obstruction and hypoxaemia. Anaesth Intensive Care 2008, 36:379-384.

14. Catley DM, Thornton C, Jordan C, Lehane JR, Royston D, Jones JG: Pronounced, episodic oxygen desaturation in the postoperative period: its association with ventilatory pattern and analgesic regimen. Anesthesiology 1985, 63:20-28.

15. Kapur VK: Obstructive sleep apnea: diagnosis, epidemiology, and economics. Respir Care 2010, 55:1155-1167.

16. Redolfi S, Yumino D, Ruttanaumpawan P, Yau B, Su MC, Lam J, Bradley TD: Relationship between overnight rostral fluid shift and obstructive sleep apnea in nonobese men. Am J Respir Crit Care Med 2009, 179:241-246.
17. Desborough JP: The stress response to trauma and surgery. $\mathrm{Br} J$ Anaesth 2000, 85:109-117.

18. Imeri L, Opp MR: How (and why) the immune system makes us sleep. Nat Rev Neurosci 2009, 10:199-210.

19. Clinton JM, Davis CJ, Zielinski MR, Jewett KA, Krueger JM: Biochemical regulation of sleep and sleep biomarkers. J Clin Sleep Med 2011, 7:S38-42.

20. Knill RL, Moote CA, Skinner MI, Rose EA: Anesthesia with abdominal surgery leads to intense REM sleep during the first postoperative week. Anesthesiology 1990, 73:52-61.

21. Rosenberg J, Wildschiodtz G, Pedersen MH, von Jessen F, Kehlet H: Late postoperative nocturnal episodic hypoxaemia and associated sleep pattern. Br J Anaesth 1994, 72:145-150.

22. Kavey NB, Ahshuler KZ: Sleep in herniorrhaphy patients. Am J Surg 1979, 138:683-687.

23. Loadsman JA, Hillman DR: Anaesthesia and sleep apnoea. Br J Anaesth 2001, 86:254-266.

24. Rosenberg J, Oturai P, Erichsen CJ, Pedersen MH, Kehlet $\mathrm{H}$ : Effect of general anesthesia and major versus minor surgery on late postoperative episodic and constant hypoxemia. J Clin Anesth 1994, 6:212-216.

25. Finkel KJ, Searleman AC, Tymkew H, Tanaka CY, Saager L, Safer-Zadeh E, Bottros M, Selvidge JA, Jacobsohn E, Pulley D, Duntley S, Becker C, Avidan MS: Prevalence of undiagnosed obstructive sleep apnea among adult surgical patients in an academic medical center. Sleep Med 2009, 10:753-758.

26. Gross JB, Bachenberg KL, Benumof JL, Caplan RA, Connis RT, Cote CJ, Nickinovich DG, Prachand V, Ward DS, Weaver EM, Ydens L, Yu S, American Society of Anesthesiologists Task Force on Perioperative Management: Practice guidelines for the perioperative management of patients with obstructive sleep apnea: a report by the American Society of Anesthesiologists Task Force on Perioperative Management of patients with obstructive sleep apnea. Anesthesiology 2006, 104:1081-1093. quiz 1117-1088.

27. Liu SS, Chisholm MF, John RS, Ngeow J, Ma Y, Memtsoudis SG: Risk of postoperative hypoxemia in ambulatory orthopedic surgery patients with diagnosis of obstructive sleep apnea: a retrospective observational study. Patient Saf Surg 2010, 4:9.

28. Redline S, Kump K, Tishler PV, Browner I, Ferrette V: Gender differences in sleep disordered breathing in a community-based sample. Am J Respir Crit Care Med 1994, 149:722-726.

29. Ficker JH, Wiest GH, Wilpert J, Fuchs FS, Hahn EG: Evaluation of a portable recording device (Somnocheck) for use in patients with suspected obstructive sleep apnoea. Respiration 2001, 68:307-312.

30. Calleja JM, Esnaola S, Rubio R, Duran J: Comparison of a cardiorespiratory device versus polysomnography for diagnosis of sleep apnoea. Eur Respir J 2002, 20:1505-1510.

doi:10.1186/1754-9493-8-13

Cite this article as: Roggenbach et al.: Incidence of perioperative sleepdisordered breathing in patients undergoing major surgery: a prospective cohort study. Patient Safety in Surgery 2014 8:13.

\section{Submit your next manuscript to BioMed Central and take full advantage of:}

- Convenient online submission

- Thorough peer review

- No space constraints or color figure charges

- Immediate publication on acceptance

- Inclusion in PubMed, CAS, Scopus and Google Scholar

- Research which is freely available for redistribution 